\title{
ORIGINAL ARTICLE \\ Maize diversity associated with social origin and environmental variation in Southern Mexico
}

\author{
Q Orozco-Ramírez ${ }^{1}$, J Ross-Ibarra ${ }^{2}$, A Santacruz-Varela ${ }^{3}$ and S Brush ${ }^{4}$
}

While prevailing theories of crop evolution suggest that crop diversity and cultural diversity should be linked, empirical evidence for such a link remains inconclusive. In particular, few studies have investigated such patterns on a local scale. Here, we address this issue by examining the determinants of maize diversity in a local region of high cultural and biological richness in Southern Mexico. We collected maize samples from villages at low and middle elevations in two adjacent municipalities of differing ethnicity: Mixtec or Chatino. Although morphological traits show few patterns of population structure, we see clear genetic differentiation among villages, with municipality explaining a larger proportion of the differentiation than altitude. Consistent with an important role of social origin in patterning seed exchange, metapopulation model-based estimates of differentiation match the genetic data within village and ethnically distinct municipalities, but underestimate differentiation when all four villages are taken together. Our research provides insights about the importance of social origin in structuring maize diversity at the local scale.

Heredity (2016) 116, 477-484; doi:10.1038/hdy.2016.10; published online 24 February 2016

\section{INTRODUCTION}

The past decade has seen progress in research about crop diversity linked to cultural diversity and social factors, but there is still much to understand about this complex relationship. Crop evolution and diversity depend on selection mediated both by the environment and by farmers (Harlan, 1975). Previous research has shown that social factors such as ritual use, identification as indigenous or mestizo, or even simple aesthetics, can contribute to the maintenance of particular landraces (Bellon, 1996; Zimmerer, 1996; Brush and Perales, 2007). We might thus expect that culturally determined preferences and perceptions have molded crop populations, but demonstrating the role of cultural diversity in generating crop diversity has been more difficult. Differentiation of maize populations and other crop populations by cultural variation was suggested long ago (Anderson, 1946; Hernández, 1972), but only recently has empirical data been reported (Perales et al., 2005; Labeyrie et al., 2014).

In México, most maize farmers select seed for use in each coming year, and this selection contributes toward maintaining distinctive morphological traits in the face of abundant pollen flow and extensive seed movement (Louette and Smale, 2000; Ortega-Paczka, 2003; Pressoir and Berthaud, 2004a). The diversity resulting from farmers' management has conventionally been classified as races, and there are 59 maize races accepted based on research using extensive morphological and isozyme data (Sánchez et al., 2000). Cultural differences between groups may be expressed as preferences for colors, textures and uses for particular varieties (Ortega-Paczka, 2003), and also serve to erect barriers to the movement of seed (Hernández, 1972). Consistent with this, many workers have documented correlations between ethnolinguistic and biological diversity (Maffi, 2005), but the relationship between these factors is complex, in part, because ethnolinguistic groups often inhabit different environments and ecological niches (Brush, 2004). In contrast to the popular assumption that there is a direct relationship between ethnolinguistic diversity and maize diversity, there is little research that has formally and systematically addressed that interaction.

Genetic research describes continuous variation among maize, although regional clusters are apparent (Matsuoka et al., 2002; Vigouroux et al., 2008). Clustering is more evident in the use of morphological traits than with genetic markers to assess relationships among ecogeographic regions (Doebley et al., 1985; Sánchez and Goodman, 1992; Sánchez et al., 2000). Using morphological characteristics that are under farmer selection, social scientists and plant biologists have shown that farmers maintain morphologically distinct maize populations at much smaller regional scales (Pressoir and Berthaud, 2004a; Perales et al., 2005). Particularly, Perales et al. (2005) found that ethnolinguistic diversity in the same environment was linked to maize morphological diversity, but not to genetic differentiation. In contrast to the findings of Pressoir and Berthaud (2004b) and Perales et al. (2005); van Etten et al. (2008) found that maize populations from different villages within a small, culturally homogeneous region in Guatemala are both genetically and phenotypically separated. They confirmed, however, the central finding of the Mexican case studies that social origin has a significant role in determining the patterns of maize in the region. Interestingly, maize diversity in NW Guatemala was more discernible between communities than between regions, a finding that van Etten et al. (2008)

${ }^{1}$ Centro de Investigaciones en Geografía Ambiental, UNAM, Antigua Carretera a Pátzcuaro, Morelia, Michoacán, México; ${ }^{2}$ Department of Plant Sciences, Center for Population Biology, and Genome Center, University of California, Davis, CA, USA; ${ }^{3}$ Colegio de Postgraduados. Montecillo, Texcoco, Estado de México, México and ${ }^{4}$ Department of Human Ecology, University of California, Davis, CA, USA

Correspondence: Dr Q Orozco-Ramírez, Centro de Investigaciones en Geografía Ambiental, UNAM, Antigua Carretera a Pátzcuaro, Col. San José de la Huerta 8701, Morelia, Michoacán 58190, México.

E-mail: qorozco@gmail.com

Received 22 June 2015; revised 19 December 2015; accepted 22 December 2015; published online 24 February 2016 
attribute to patterns of seed exchange at local and regional levels and to diffusion of innovations at the regional level.

This paper examines maize diversity and population structure at the local scale and their relation to both ethnolinguistic variation and environmental variation (elevation) in southern Mexico. We studied farmers who speak either Chatino or Mixtec, two languages of the Oto-Manguean family that have been separated for $\sim 4700$ years (Kaufman, 1990). We collected maize samples from two environments - low and middle elevation - in two neighboring, indigenous municipalities with different language affiliations. We hypothesized that maize collections from the same municipality would be more similar than those from different municipalities, even though comparable environmental variation occurs within each. We found the effects of social origin (municipality) in structuring morphological and genetic diversity stronger than that of elevation. Application of a metapopulation model suggests that genetic differentiation is because of the lack of seed flow between municipalities.

\section{MATERIALS AND METHODS}

\section{Study site}

Fieldwork was carried out in the Sierra Sur of Oaxaca (Figure 1). This mountainous range extends along the Pacific Coast from southern Jalisco to the Isthmus of Tehuantepec in the state of Oaxaca. We worked in the Mixtec municipality of Santiago Amoltepec and the Chatino municipality of Santa Cruz Zenzontepec. These indigenous communities have an ancient and shared history: their townships are only $12 \mathrm{~km}$ apart and they have been affected by the same regional and historical dynamics. The topography is abrupt, with mountains, canyons and hills leading to elevation variation from 105 to 2150 meters above sea level (masl). The climate is hot in the lowlands and temperate in the higher elevations. The mean annual temperature is $26^{\circ} \mathrm{C}$ in the lowlands and $18{ }^{\circ} \mathrm{C}$ in the upper elevations. The rainy season starts in May and ends in October, with an average from 1500 to $2000 \mathrm{~mm}$ precipitation per year (INEGI, 2013). Humidity differs strongly between the lowlands and highlands and is affected by the exposure in the hills. Soil diversity is high because of the complex geology; according to the most detailed available information, Litosol and Regosol eutrico are the most important soil types (INEGI, 2013). In general, soils present some level of erosion because of agricultural practices, runoff and wind. Municipalities are integrated internally through local governments and markets. Beyond some seed in backyard gardens, no hybrid or improved seed has been planted in the area. Crop management is similar in both municipalities, the only difference being the use of fertilizer in the Chatino municipality, Zenzontepec and not in the Mixtec municipality, Amoltepec.

\section{Maize collections and reciprocal common gardens}

To test whether maize diversity and population structure are shaped by social origin and/or environmental factors, maize collections and common garden experiments with morphological characterization were performed. Four villages were selected: one Chatino and one Mixtec at middle elevation (1000-1300 masl) identified as Ch-M and M-M, respectively; and one Chatino and one Mixtec in the lowlands (400-600 masl), identified as Ch-L and M-L. A detailed description of the sampling and common gardens are described elsewhere (Orozco-Ramírez et al., 2014). We collected a total of 135 maize samples from the four villages ( 33 from M-M, 23 from M-L, 44 from Ch-M and 35 from Ch-L). Each maize sample consisted of 12 seed quality ears of each farmer-identified type that the household planted in the previous year. Ecological information and management of each sample was recorded by a survey, we considered that each sample represents one maize population. The samples of each village were grouped by local name and race, and organized according to variation in ear morphology. Five maize samples from each village were selected to plant in the common gardens; these samples resembled the total variation of maize in that particular village. In this analysis, we used only the data from two common gardens under fertilization treatment, one in the Chatino village low elevation (Ch-L) and another in Mixtec middle elevation (M-M). These were the fields with the best soil conditions to perform morphological characterization. Each of the common gardens had a complete random block design with three repetitions,
60 experimental units per garden ( 4 villages $\times 5$ samples $\times 3$ blocks). Each experimental unit had four furrows, each $5 \mathrm{~m}$ long and $0.8 \mathrm{~m}$ wide. Morphological data recorded from common gardens included days to anthesis, days to silking, tassel branches, tassel length, stem diameter, leaf length, leaves per plant, leaf width, ear height on the plant, plant height, ear diameter, ear length, grain rows, kernels per row and cob diameter. Twenty plants were measured from the two rows in the center. Flowering time was recorded when $50 \%$ of the plants had reached anthesis or were silking. For ear variables, all the plants of one row located in the center of the plot were harvested. We averaged each variable over plots.

\section{Molecular analysis}

Molecular analysis was carried out at the Colegio de Postgraduados, Mexico. We used the same 20 maize samples (but not the same physical individuals) as used in common gardens for microsatellite genotyping. DNA was extracted from 10 individuals randomly selected for each sample, using the standard protocol prescribed by the ChargeSwitch gDNA Plant Kit (Invitrogen, Carlsbad, CA, USA). We used 100-150 mg of seedling tissue. DNA extraction was made by a King Fisher Flex (Thermo Scientific, Waltham, MA, USA) automatic extractor. The DNA samples selected had a DNA concentration above $50 \mathrm{ng} \mathrm{ll}^{-1}$ and an absorbance ratio from 1.40 to 1.80 at $260 / 280 \mathrm{~nm}$ wavelength. The DNA was evaluated by a Nanodrop 2000 Spectrophotometer (Thermo Scientific). Extracted samples were genotyped for 15 microsatellite loci, listed in Supplementary Appendix Table A1. These markers were chosen from a larger group of SSRs (simple sequence repeats) optimized for multiplexing, and proved to be efficient to reveal genetic diversity in maize. For more information about these SRRs, see http://www.maizegdb.org/data_center/ssr. Fluorescently labeled primers (ROX, 6-FAM, HEX) were obtained for these loci (Invitrogen). Multiple PCRs were performed in a $25 \mu \mathrm{l}$ reaction volume, containing $4 \mathrm{pmol} \mathrm{\mu l}^{-1}$ of $\mathrm{R}$ and $\mathrm{F}$ primer (Invitrogen), $0.16 \mathrm{~mm}$ of dNTP mix (Promega, Madison, WI, USA), $1.2 \mathrm{~mm}$ of $\mathrm{MgCl}_{2}$ (Promega), $0.8 \times$ of GoTaq flexi buffer (Promega), $1 \mathrm{U}$ of GoTaq flexi DNA polymerase (Promega) and $25 \mathrm{ng}$ of DNA. The amplification program was: $95^{\circ} \mathrm{C}$ for $4 \mathrm{~min}$, followed by 25 cycles of $95^{\circ} \mathrm{C}$ for $1 \mathrm{~min}, 55^{\circ} \mathrm{C}$ for $2 \mathrm{~min}$ and $72^{\circ} \mathrm{C}$ for $2 \mathrm{~min}$, and then followed by extension at $72{ }^{\circ} \mathrm{C}$ for $60 \mathrm{~min}$. PCR was performed in a GeneAmp PCR System 9700 (Applied Biosystems, Foster City, CA, USA). PCR products were analyzed by capillary electrophoresis in a 3130 Genetic Analyzer (Applied Biosystems). Fragment sizes were scored using GeneMapper v4.0 (Applied Biosystems).

\section{Statistical analysis}

Maize population structure based on morphological traits from the common gardens was analyzed by principal component analysis. We excluded days to silking and height of ear in the plant because these variables were highly correlated to days to tasseling and plant height, respectively. Data were standardized by subtracting the mean from each observation and dividing by the standard deviation. The unit of analysis was maize sample at each plot in the common gardens. To define the effect of elevation and social origin (different municipality) in structuring populations using morphological traits, we did a permutational multivariate analysis of variance using distance matrices (Anderson, 2001). This is a nonparametric method that partitions a distance matrix among sources of variation. For this analysis, we used the same variables as for the principal component analysis. The distance matrix was calculated using the Euclidian method on the standardized data and we allowed for 9999 permutations to calculate $\mathrm{F}$ statistics and to have an ample margin to reject the null hypothesis at an $\alpha$-level of 0.05 . For this analysis, we applied the function adonis in the package vegan (Oksanen et al., 2015) for R (R Core Team, 2014).

We used model-based clustering to evaluate population structure as implemented in the software structure 2.3.4 (Pritchard et al., 2000), using the admixture model with correlated allele frequencies and allowing the model to use location information for the samples to assist the clustering. The estimated proportion of each cluster forming an individual genome $(q)$ was calculated for $K$ ranging from 1 to 10 populations, with 10 runs for each $K$-value. We used a burn-in period of 100000 and 100000 iterations for estimating the parameters. The criterion suggested by Evanno et al. (2005), based on the second-order rate of change in the log probability of data between successive $K$-values, was used to determine the most likely number of clusters $(K)$. 


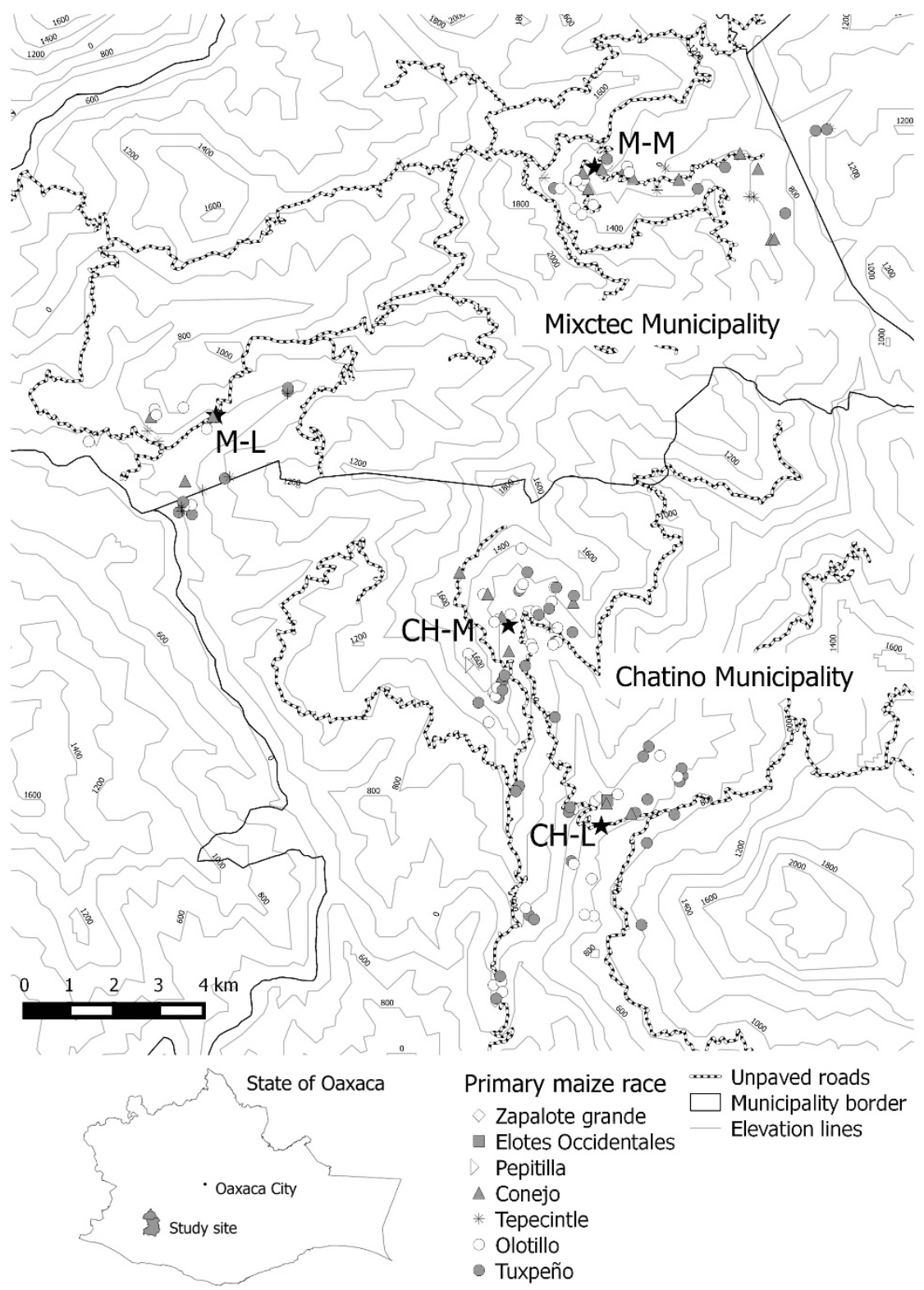

Figure 1 Map of villages and collections.

Owing to low genetic differentiation among maize samples within village in the software STRUCTURE, we treat each village as a single population to then perform a locus-by-locus analysis of molecular variance (AMOVA) (Excoffier et al., 1992) grouping villages according to municipality. We preferred locus-bylocus AMOVA because there were some missing data and we included individual level in the calculations. Significance was calculated using 16000 permutations and estimates of the proportion of variation at different levels were calculated as a weighted average across loci. Because each village within a municipality is located at different elevation, when testing within municipality, we are testing for the effect of environment in structuring the population. We also calculated a matrix of genetic distance $\left(\mathrm{F}_{\mathrm{ST}}\right)$ (Wright, 1951) among villages based on the number of different alleles using Arlequin 3.5 (Excoffier et al., 2005), with significance $(\alpha=0.05)$ calculated after 1000 permutations.

Finally, we used the model proposed by van Heerwaarden et al. (2010) to estimate genetic differentiation because of seed management and seed flow. This approach models a collection of maize fields as a metapopulation and uses parameters from maize farmers' practices in traditional agricultural systems to estimate $\mathrm{F}_{\mathrm{ST}}$ following Slatkin (1991). We compared model-based estimates of $\mathrm{F}_{\mathrm{ST}}$ to $F_{S T}$ calculated from our SSR genotyping. $F_{S T}$ was calculated for each village and globally using Arlequin 3.5 (Excoffier et al., 2005). $\mathrm{F}_{\mathrm{ST}}$ confidence intervals were calculated over 2000 bootstraps. The model uses these parameters: number of demes $(n)$, number of ears planted per deme $\left(N_{\mathrm{f}}\right)$, total number of plants per deme $(N)$, number of migrating ears $\left(N_{\mathrm{fm}}\right)$, replacement probability $(e)$, migration (mixture proportion) proportion $\left(m=N_{\mathrm{fm}} / N_{\mathrm{f}}\right)$, proportion of seed mixture $\left(p_{\mathrm{m}}\right)$ and proportion pollen migration $\left(m_{\mathrm{g}}\right)$. Values used for each parameter are in Table 1, unless otherwise stated data used came from our field surveys (OrozcoRamírez et al., 2014). Values for each parameter were obtained by village (Table 1) and were averaged or summed accordingly to obtain $\mathrm{F}_{\mathrm{ST}}$ for several hierarchical levels: by municipality, by elevation and for all villages together as shown in Table 2. Number of demes $(n)$ were calculated by multiplying number of households by mean number of samples over households for each village. Number of ears planted per deme $\left(N_{\mathrm{f}}\right)$ was calculated from average planted area, seed sown per hectare, average kernel weight in the region (Aragón-Cuevas et al., 2012) and the average number of kernels used as seed from each ear. The total number 
Table 1 Seed management parameters for $\mathrm{F}_{\mathrm{ST}}$ estimation ${ }^{\mathrm{a}}$

\begin{tabular}{|c|c|c|c|c|c|}
\hline Parameter & $M-M$ & $M-L$ & $C h-M$ & $C h-L$ & Total/mean \\
\hline \multicolumn{6}{|l|}{ Data from surveys } \\
\hline Number of households & 152 & 49 & 206 & 219 & 626 \\
\hline Average planting area (ha) & 0.52 & 0.61 & 0.56 & 0.78 & 0.62 \\
\hline Seed sow per hectare $(\mathrm{kg})$ & 16 & 16 & 16 & 16 & 16 \\
\hline Total seed used per deme (kg) & 8.32 & 9.76 & 8.96 & 12.48 & 9.92 \\
\hline Mean of quantity seed exchange (kg) & 3.3 & 4 & 5 & 4.9 & 4.2 \\
\hline Proportion of exchange seed & 0.40 & 0.41 & 0.56 & 0.39 & 0.42 \\
\hline \multicolumn{6}{|l|}{ Parameters for the model } \\
\hline Number of demes $(n)$ & 287 & 65 & 323 & 307 & 970 \\
\hline Number of ears planted per deme $\left(N_{f}\right)$ & 96 & 112 & 103 & 143 & 114 \\
\hline Proportion of seed mixture $\left(p_{\mathrm{m}}\right)$ & 0.00125 & 0.00106 & 0 & 0 & 0.00058 \\
\hline
\end{tabular}

Abbreviations: Ch-L, Chatino at low elevation; Ch-M, Chatino at middle elevation; M-L, Mixtec at low elevation; M-M, Mixtec at middle elevation.

a Using van Heerwaarden et al. (2010) metapopulation model to estimate genetic structure.

bestimated according to mean row and grain number per ear used for seed and using the average kernel weight estimated by Aragón-Cuevas et al. (2012) for landraces from the region.

Table 2 Results of van Heerwaarden et al. (2010) metapopulation model to estimate genetic structure based on seed management

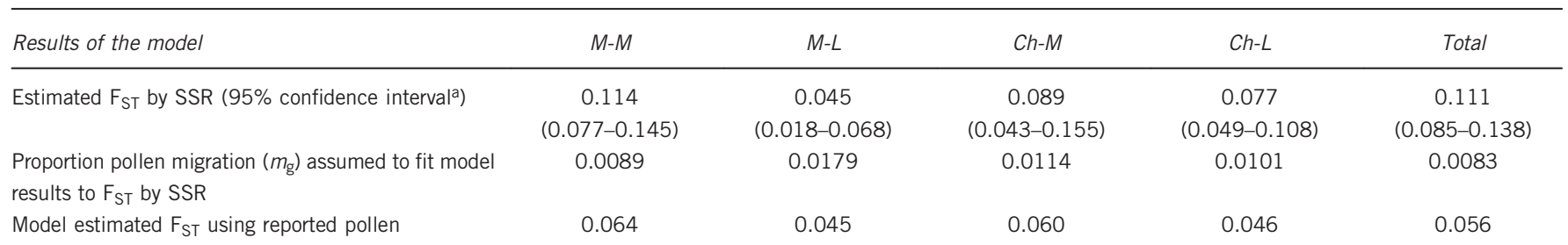

migration (0.018) by Messeguer et al. (2006)

Mixtec villages

$\begin{array}{cc}0.089(0.063-0.109) & 0.082(0.056-0.115) \\ 0.0112 & 0.0112 \\ 0.059 & 0.053\end{array}$

Estimated $\mathrm{F}_{\mathrm{ST}}$ by SSR $\left(95 \%\right.$ confidence interval $\left.{ }^{\mathrm{a}}\right)$

Proportion pollen migration $\left(m_{\mathrm{g}}\right)$ assumed to fit model results to $\mathrm{F}_{\mathrm{ST}}$ by SSR

Model estimated $\mathrm{F}_{\mathrm{ST}}$ using reported pollen migration (0.018) by

Messeguer et al. (2006)
Middle elevation villages Low elevation villages

$\begin{array}{ccc}0.120(0.087-0.156) & 0.094(0.071-0.114) & 0.111(0.085-0.138) \\ 0.0085 & 0.0087 & 0.083 \\ 0.0089 & 0.0089 & 0.086 \\ & & \\ 0.064 & 0.050 & \end{array}$

Estimated $\mathrm{F}_{\mathrm{ST}}$ by SSR $\left(95 \%\right.$ confidence interval $\left.{ }^{\mathrm{a}}\right)$

Proportion pollen migration $\left(m_{\mathrm{g}}\right)$ assumed to fit model results to $\mathrm{F}_{\mathrm{ST}}$ by SSR

Proportion pollen migration $\left(m_{\mathrm{g}}\right)$ assumed to fit model results to $\mathrm{F}_{\mathrm{ST}}$ by SSR

setting seed migration frequency $(m)$ to $\sim 0^{\mathrm{b}}$ and seed mixture $\left(p_{\mathrm{m}}\right)$ to 0

Model estimated $\mathrm{F}_{\mathrm{ST}}$ using reported pollen migration $(0.018)$ by

Messeguer et al. (2006)

Abbreviations: Ch-L, Chatino at low elevation; Ch-M, Chatino at middle elevation; M-L, Mixtec at low elevation; M-M, Mixtec at middle elevation; SSR, simple sequence repeat.

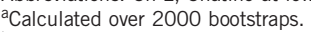

${ }^{\mathrm{b}}$ The model does not accept zero migrating ears, we used 0.000001

of plants per deme $(N)$ was estimated by multiplying the average kernels per ear by $N_{\mathrm{f}}$. The number of migrating ears $\left(N_{\mathrm{fm}}\right)$ was calculated from seed exchange averaged over farmers in each village $(\mathrm{kg})$. First, we obtained the proportion of seed exchanged with respect to total seed planted and then multiplied that proportion by $N_{\mathrm{f}}$. Replacement probability (e) was calculated as the proportion of new seed lots with respect to the total reported for the previous season. Initial values of the proportion of pollen migration $\left(m_{\mathrm{g}}\right)$ were taken from the literature (Messeguer et al., 2006), but these were later fitted to the observed $\mathrm{F}_{\mathrm{ST}}$ data.

\section{RESULTS}

Maize diversity in the area of study

On average, the number of landraces cultivated by a single farmer ranges from 1.33 in $\mathrm{M}-\mathrm{L}$ to 1.89 in $\mathrm{M}-\mathrm{M}$. In $\mathrm{M}-\mathrm{M}$, the majority of farmers $(67 \%)$ have two landraces. In the other three villages, most farmers had only one landrace. In M-L, fewer farmers had two landraces than in the other three villages. Only in Ch-M did farmers have four landraces, but the percentage of farmers with more than 
three landraces was very low, and most in that village have only one landrace. In total, we found seven racial groups in the four villages (Tuxpeño, Olotillo, Conejo, Tepecintle, Pepitilla, Elotes occidentales and Zapalote grande). A test for independence of race frequency by village finds little support for a dependence on elevation $(P$-value $=0.06793$, 1000 Monte Carlo simulations), but strong support for dependence on municipality ( $P$-value $=0.0001,1000$ Monte Carlo simulations). Mixtec communities have more of the Conejo and Tepecintle races, and Chatino villages have more of the Olotillo and Tuxpeño races (Figure 1 and see Supplementary Appendix Table A2).

Maize population structure based on morphological traits

Principal component analysis reveals a continuum of maize morphological diversity across the region. The plot of the first two principal components does not show clearly separate groups in either common garden (Figure 2). However, in both common gardens it is possible to see greater clustering of samples when labeled by municipality (Figures $2 \mathrm{a}$ and $\mathrm{c}$ ) than by elevation (Figures $2 \mathrm{~b}$ and $\mathrm{d}$ ). The first component (PC1) for the M-M garden shows the most important variables are leaf number, leaf width, plant height, stem diameter and leaf length, meaning that PC1 accounts overall for plant size, separating large and small plants (Supplementary Appendix Table A3). For the second component (PC2), tasseling, ear diameter, row number and cob diameter have a large loading. PC2 differentiates earlier maturing plants and fatter ears. Principal component analysis for the Ch-L common garden shows the first component (PC1) accounting in general for plant size and the second for fatter ears (PC2).
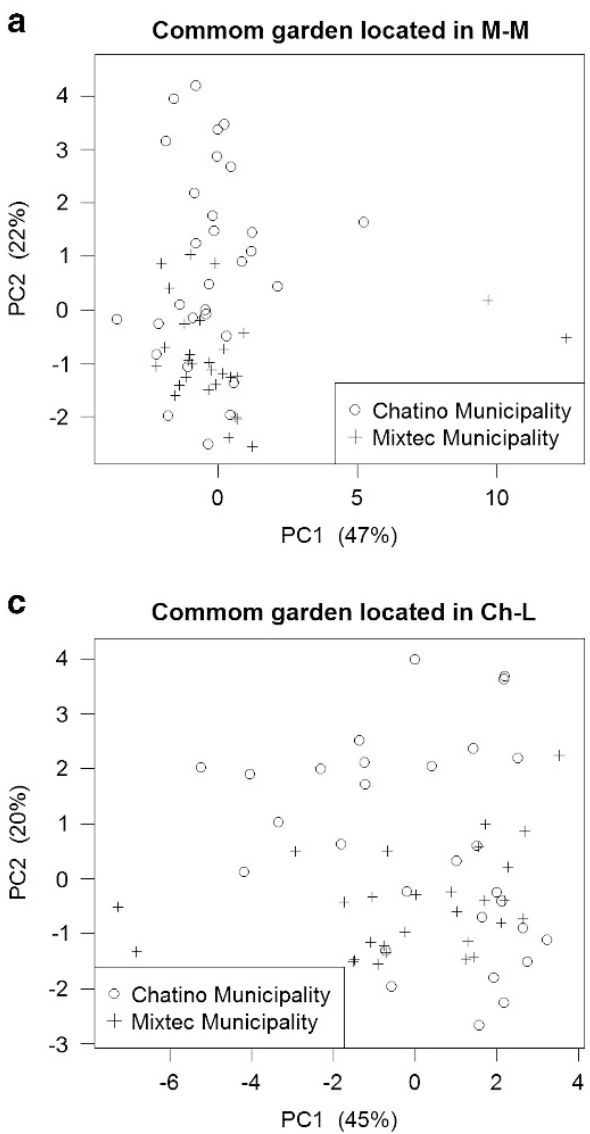

According to permutational multivariate analyses of variance, the main effect of municipality was significant in structuring morphological variation, but neither elevation nor the interaction between elevation and municipality were significant (Table 3). Comparison of the mean sum of squares (Anderson, 2001) suggests that municipality has a stronger effect than elevation in structuring maize populations (Table 3). Nonetheless, there are some differences between common gardens. The effect of municipality was weaker in the low elevation garden, perhaps because of the lower overall morphological variation observed.

\section{Maize population structure based on molecular markers}

Results from software STRUCTURE suggested the existence of two clusters defined by municipality (Figure 3 ). The highest value of $\Delta K$ was found at $K=2$, but at higher values of $K$ the Mixtec area shows separation between villages. Chatino villages are not similarly separated. Most individuals show evidence of admixture, and there is no correspondence between maize race name and STRUCTURE results. The only exception is a sample from M-M of the Conejo race, which at higher values of $K(\geqslant 4)$ forms a stable cluster with low admixture. Samples never cluster by elevation.

Our AMOVA finds relatively strong population structure (Table 4). Most of the genetic variation (73\%) was found within populations, with less variation assigned to municipality (4\%) and elevation (1.75\%). The results of the AMOVA are confirmed by the matrix of pairwise genetic distance $\left(F_{\mathrm{ST}}\right)$ among villages, although all values are low. $\mathrm{F}_{\mathrm{ST}}$ between villages of the same municipality (0.019 Mixtec, 0.021 Chatino) are

b
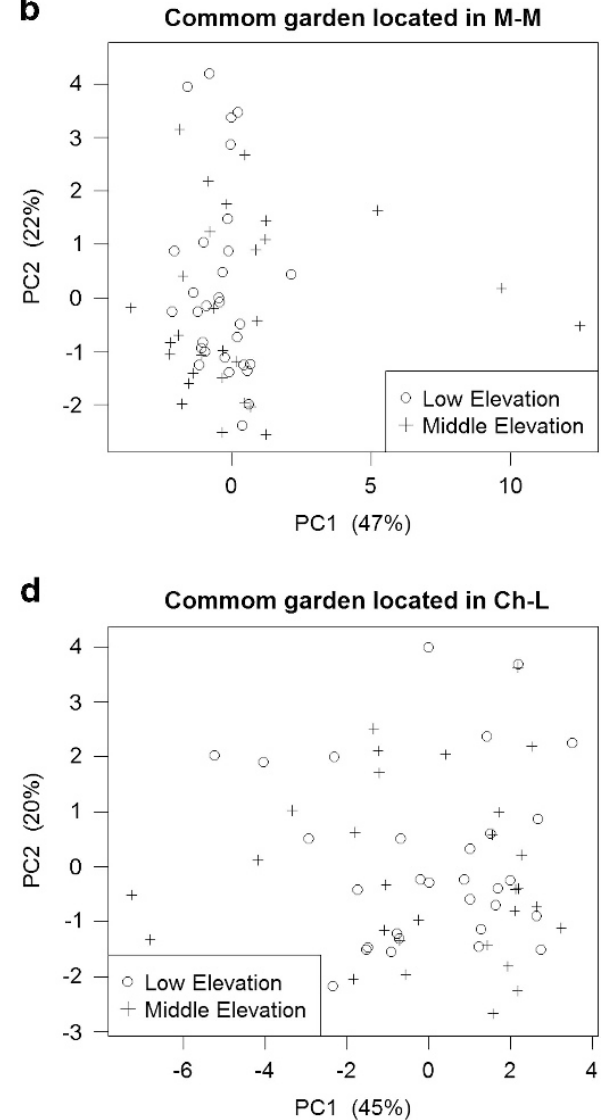

Figure 2 Principal component analysis plot (PC1 vs PC2) for morphological traits sorted by municipality, and elevation, data from middle and lowlands common gardens. 
lower than between populations of the same elevation but different municipalities (0.041 middle, 0.066 low). $F_{\text {ST }}$ between villages from different municipalities and different elevations are also large (M-M vs Ch-L is 0.059 , M-L vs Ch-M 0.045), but the largest difference is between Mixtec Lowlands and Chatino Lowlands (0.066). All $F_{\mathrm{ST}}$ values are significant $(\alpha=0.05)$ calculated after 1000 permutations.

Table 3 Permutational multivariate analysis of variance on Euclidean distances matrices for plant morphology traits for each common garden (M-M, Ch-L)

\begin{tabular}{lccccc}
\hline Factor & D.f. & Sums of sqs & Mean sqs & F. model & $\operatorname{Pr}(>\mathrm{F})$ \\
\hline $\begin{array}{l}\text { M-M common garden } \\
\quad\end{array}$ & 1 & 17.8 & 17.8 & 1.5 & 0.200 \\
$\quad$ Elevation & 1 & 70.1 & 70.1 & 5.9 & 0.000 \\
$\quad$ Municipality & 56 & 666.0 & 11.9 & 0.9 & \\
$\quad$ Residuals & 58 & 754.0 & & & \\
Total & & & & & \\
& & & & & \\
Ch-L commom garden & 1 & 16.8 & 16.8 & 1.4 & 0.235 \\
$\quad$ Elevation & 1 & 46.0 & 46.0 & 3.7 & 0.010 \\
$\quad$ Municipality & 56 & 691.2 & 12.3 & 0.9 & \\
$\quad$ Residuals & 58 & 754.0 & & & \\
$\quad$ Total & 58.0 & & & &
\end{tabular}

Abbreviations: Ch-L, Chatino at low elevation; Ch-M, Chatino at middle elevation; M-L, Mixtec at low elevation; M-M, Mixtec at middle elevation.

aUsing 9999 permutations, two levels for social origin (Mixtec municipality and Chatino municipality) and two levels for elevation (low and middle elevation).
We tested population structure due to race by AMOVA. We confirmed our STRUCTURE results, finding no evidence of differentiation between racial groups $\left(\mathrm{F}_{\mathrm{CT}}=0.004, P\right.$-value $\left.=0.295\right)$, but there was important variation among populations within racial groups $\left(\mathrm{F}_{\mathrm{SC}}=0.108\right.$, $P$-value $=0.000)$. According to SSR's racial grouping seems artificial (See Supplementary Appendix Table A.4).

\section{Metapopulation model}

We used the metapopulation model of van Heerwaarden et al. (2010) to estimate $\mathrm{F}_{\mathrm{ST}}$ and theoretical pollen migration based on seed management and exchange from our surveys. Within villages, to obtain similar modeled values to $\mathrm{F}_{\mathrm{ST}}$ to those calculated by SSR's, we had to assume similar pollen migration rates to those in the literature (Messeguer et al., 2006), with the exception of the M-M village where a very low pollen migration proportion (0.0089) was needed, the range in the other three villages was from 0.010 to 0.018 (Table 2). We next asked whether the model can be extended to villages within municipalities, and were able to find a reasonable fit of the model using pollen flow values within the range used for within-village comparisons (0.0112), supporting the idea that gene flow between villages of the same ethnolinguistic group is similar to that than within villages. In contrast, fitting the model to elevation groupings or the entire study region, required much lower pollen flow estimates: 0.0087 for lowlands, 0.0085 for middle elevation and 0.0083 for the region (Table 2).
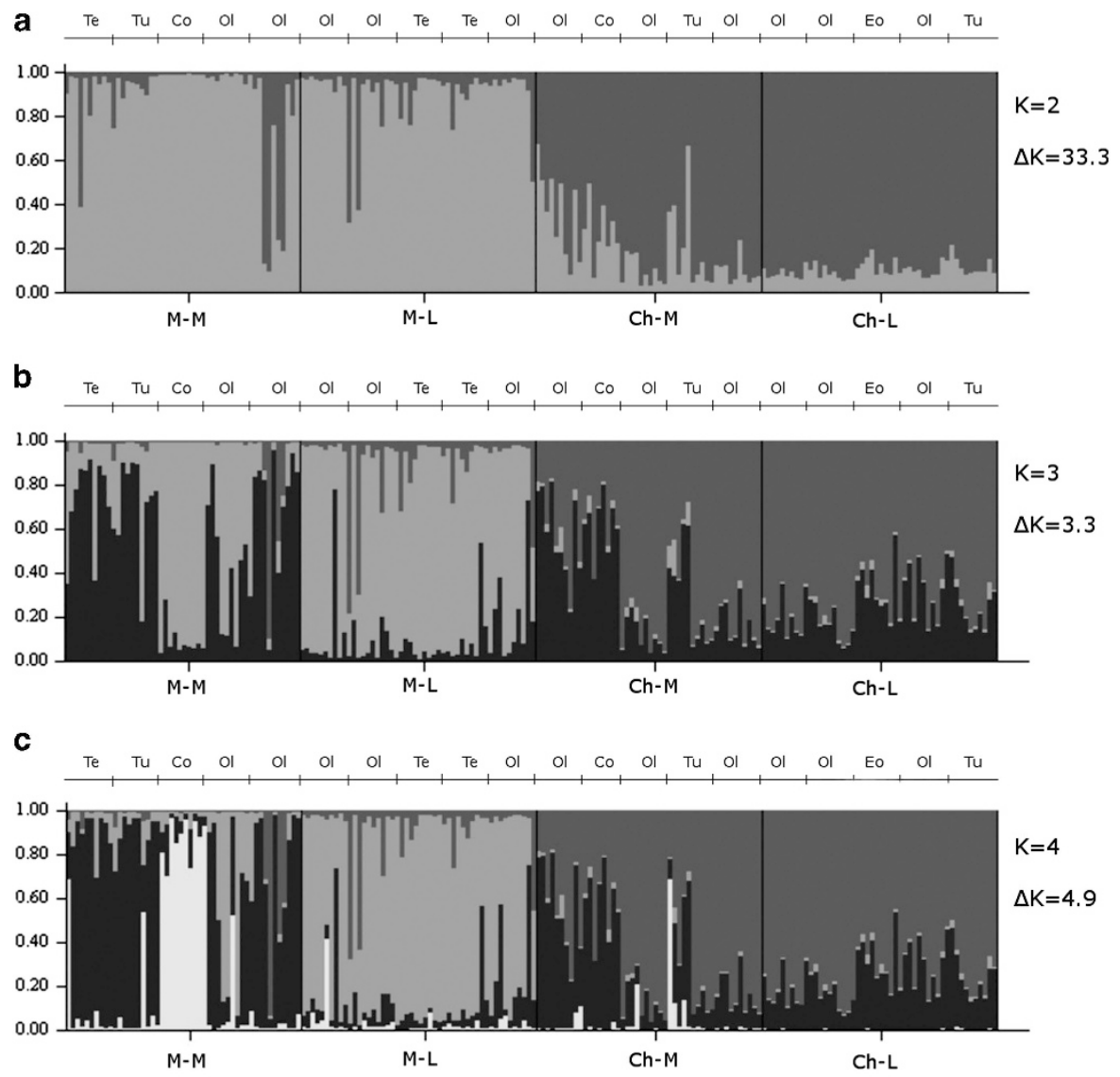

Maize races: Te: Tepecintle; Tu: Tuxpeño; Co: Conejo; Ol: Olotillo; Eo: Elotes occidentales

Figure 3 STRUCTURE graphical results assuming two (a), three (b) and four (c) groups, after a burning period of 30000 iterations and 1000000 replications for estimations. Each individual plant is represented by a vertical line. Each color represents the membership to each cluster $(k)$. Labels in the $\mathrm{x}$ axis show the village of origin. 
Table 4 Genetic structure as revealed by AMOVA and F $_{\text {ST }}$

\begin{tabular}{|c|c|c|c|c|c|}
\hline Source of variation & Sum of squares & Variance components & Percentage variation & Fixation indices & P-value \\
\hline Between municipalities & 48.40 & 0.21 & 4.04 & $F_{C T}=0.040$ & 0.000 \\
\hline Among villages within municipality (elevation effect) & 27.85 & 0.09 & 1.75 & $\mathrm{~F}_{\mathrm{SC}}=0.018$ & 0.000 \\
\hline Within individuals & 648.00 & 3.85 & 72.92 & $\mathrm{~F}_{\mathrm{IT}}=0.271$ & 0.000 \\
\hline Total & 1721.94 & 5.29 & & & \\
\hline
\end{tabular}

Abbreviation: AMOVA, analysis of molecular variance.

Notes: $P$-value calculated after 16000 permutations.

\section{DISCUSSION}

Results from our comparison of genetic and morphological variation among maize landraces cultivated by Mixtec and Chatino farmers support the hypothesis that ethnolinguistic differences could shape diversity as much or more than the environment in this particular region. Plant morphological characteristics measured in the common gardens display considerable variation without strong clustering. Nevertheless, it is possible to see the effect of municipality but not elevation in structuring the population (Table 3). All statistical methods used to analyze molecular markers show greater support for structure because of social origin than environment (elevation).

In a previous paper, we have shown that adaptation of local landraces is not a primary reason for landrace distribution in the region. We found that landraces from $\mathrm{Ch}-\mathrm{L}$ yield better in all four villages (Orozco-Ramírez et al., 2014). Other factors, besides environment and ethnicity, help determine landrace distribution, such as infrastructure (roads) and markets. From our ethnographic work, we know roads are relatively recent to the region. Previously, the region's villages were connected by foot traffic (Orozco-Ramírez, 2014). From our surveys, we know of seed exchange among villages with no road access, and the average distance between those villages is $8.5 \mathrm{~km}$. Seed exchange involving moving by both foot and vehicles occurred over an average distance of $70 \mathrm{~km}$. Most external seed exchange happened among villages of the same ethnicity (65\%, averaged over all villages) or with Spanish-speaking towns (31\%). The distance by foot between villages of different ethnicities is actually smaller in some cases than the distance between villages of the same ethnicity having seed exchange, consequently we cannot argue that maize population differentiation is a consequence of ease of transport or access. In relatively rare instances (4\%), seed exchange occurred among villages of different ethnicities, suggesting that ethnicity matters to defining seed acquisition (Orozco-Ramírez, 2014).

Our results contrast with previous findings in the Oaxaca Valley (Pressoir and Berthaud, 2004a) and Chiapas (Perales et al., 2005) that suggest social origin only impacts morphological variation directly selected by farmers. Pressoir and Berthaud (2004a) argued that cultivation in different villages and farmer's selection contribute to morphological differentiation, but that pollen migration among populations reduces genetic separation. Similarly, Perales et al. (2005) found morphological but no genetic differentiation between neighboring ethnolinguistic groups. Their surveys found that a large majority $(>70 \%)$ of farmers were interested in receiving seed from villages of a different ethnic group, suggesting that seed movement may explain the extremely low $\mathrm{F}_{\mathrm{ST}}$ values they observed. Comparing highland and lowland maize samples from four states in east-central Mexico, van Heerwaarden (2007) reports genetic differentiation according to altitude but not according to social origin within altitudes. Most research, therefore, suggests gene flow is important among maize populations from different villages and that farmers' selection is important in maintaining morphological differentiation. In contrast, we find modest morphological and genetic differentiation between ethnolinguistic areas $\left(\mathrm{F}_{\mathrm{CT}}=0.040\right)$ (Table 4) that are geographically quite close, which is larger than among village differentiation (0.003) reported by Pressoir and Berthaud (2004b) and by van Heerwaarden (2007) (0.026 for highlands and 0.027 for lowlands). Among these studies, our study focused on the smallest region followed by Pressoir and Berthaud (2004b) and van Heerwaarden (2007). Also, we found greater global differentiation, over all markers, $\left(\mathrm{F}_{\mathrm{ST}}=0.111(0.085-0.138,95 \%\right.$ confidence interval by bootstrapping)) (Table 2) than values reported by Pressoir and Berthaud (2004b) $\left(\mathrm{F}_{\mathrm{ST}}=0.011 \pm 0.002,95 \%\right.$ confidence intervals by jackknifing). Our study was carried out in a region with no roads crossing it and with no common local or regional markets. This contrasts to the situation in the Central Valleys of Oaxaca, where roads and markets unify the region and exchange commonly occurs between villages. In contrast, our results suggest that ethnolinguistic differences could effectively isolate maize populations in this region that are otherwise under similar natural and artificial selection pressures. We conclude that, at least in some cases, ethnolinguistic affiliation can reduce gene flow more than the environmental obstacles posed by altitude differences. We posit that ethnically based seed networks foster both morphological and genetic separation, an idea similar to that of Hernández (1972), who suggested that indigenous groups isolate maize populations in a way similar to geographic barriers. An important next step is to expand the research to a contiguous Zapotec municipality to improve the test of the effect of ethnicity in structuring maize populations.

Previous work has found that both genetic and morphological variation are strongly structured by elevation (Doebley et al., 1985; Benz, 1986; Bretting and Goodman, 1989; Vigouroux et al., 2008; van Heerwaarden et al., 2011). Research on the distribution of maize races in central Mexico (Perales et al., 2003) and Chiapas (Brush and Perales, 2007) found that maize races are distributed according to elevation, and common garden experiments suggest local adaptation to elevation (Mercer et al., 2008). van Heerwaarden (2007) showed close association between maize genetic structure and elevation at a regional scale in eastcentral Mexico, and genetic analyses find a significant impact of elevation on genome-wide diversity in both maize and its wild relative teosinte (Bradburd et al., 2013; Pyhäjärvi et al., 2013; Takuno et al., 2015). Contrary to these findings, we found no differentiation of maize populations by elevation (races, morphological traits and molecular markers), likely because of the much smaller geographic scale of our population sampling.

Models of metapopulation structure based on our survey data support a possible role for ethnicity in patterning genetic diversity in our study area. The metapopulation model of van Heerwaarden et al. (2010) is able to fit $\mathrm{F}_{\mathrm{ST}}$ values within most villages using pollen migration values similar to direct estimates reported in the literature (Messeguer et al., 2006) (Table 2). The strikingly high $\mathrm{F}_{\mathrm{ST}}$ and correspondingly low pollen migration required to fit the model in M-M was because of the presence of a highly distinct early maturing landrace in part of the village (Figure 3); because of differences in flowering time, we hypothesize there is likely very little pollen 
migration between this landrace and others. The model also fits well observed $\mathrm{F}_{\mathrm{ST}}$ between ethnolinguistic groups using pollen migration parameters within the range seen in individual villages (Table 2). Within elevation regimens (between ethnolinguistic groups) or among all villages, however, the model was only able to fit observed $\mathrm{F}_{\mathrm{ST}}$ values with a substantial reduction in the pollen migration parameter or with a smaller reduction in pollen migration and setting seed migration frequency to zero. Because of the good fit of the model within villages and between villages within an ethnic group, the decrease in migration (pollen or seed) required to fit the model to elevation groups or the entire data is consistent with the idea that ethnolinguistic group is a limitation to maize gene flow in this region.

Previous studies that have found morphological differences among maize from different villages have not found much differentiation at the genetic level, suggesting that selection for a particular maize ideotype cannot explain the genetic differentiation observed in our villages. Instead, we suggest that a reduction of gene flow by limited seed and pollen migration among villages of different ethnolinguistic groups has effected genetic structure both in morphological traits and in genome-wide markers. We propose that detailed investigation of seed networks is an important next step to understanding the processes that pattern genetic diversity in maize.

\section{DATA ARCHIVING}

Data available from the Dryad Digital Repository: http://dx.doi.org/ 10.5061/dryad.c25f0.

\section{CONFLICT OF INTEREST}

The authors declare no conflict of interest.

\section{ACKNOWLEDGEMENTS}

We thank CONACYT and UC MEXUS for funding this research through a doctoral scholarship and a dissertation grant. We thank Msc Flavio Aragon-Cuevas (INAFAP, Mexico) for maize racial classification; Cinthia Guzman, Laura Carrillo and Juan Sánchez (Colegio de Postgraduados, Mexico) for genotyping work; Dr Mark Grote (UC Davis) and Jonathan Fresnedo (UC Davis) for statistical advice; Joost van Heerwaarden for sharing an R script to run the metapopulation model; and farmers and authorities from Santiago Amoltepec and Santa Cruz Zenzontepec for their support and for allowing to carry out this research. We also thank CIGA-UNAM for a postdoctoral scholarship to improve the writing of this paper. JRI would like to acknowledge support from USDA Hatch project CA-D-PLS-2066-H and NSF Plant Genome award 1238014. We thank to four anonymous reviewers for theirs comments, which improved the quality of this paper.

Anderson E (1946). Maize in Mexico: a preliminary survey. Ann Missouri Bot Gard 33 $147-247$.

Anderson MJ (2001). A new method for non-parametric multivariate analysis of variance. Austral Ecol 26: 32-46.

Aragón-Cuevas F, Figueroa-Cárdenas J, Flores-Zarate M, Gaytán-Martínez M, Véles Medina J (2012). Calidad industrial de maíces nativos de la sierra sur de Oaxaca. INIFAP: Oaxaca, Mexico.

Bellon MR (1996). The dynamics of crop infraspecific diversity: a conceptual framework at the farmer level. Econ Bot 50: 26-39.

Benz BF (1986). Taxonomy and Evolution of Mexican Maize. PhD Dissertation University of Wisconsin: Madison, WI, USA.

Bradburd GS, Ralph PL, Coop GM (2013). Disentangling the effects of geographic and ecological isolation on genetic differentiation. Evolution 67: 3258-3273.

Bretting P, Goodman M (1989). Karyotypic variation in Mesoamerican races of maize and its systematic significance. Econ Bot 43: 107-124.

Brush S (2004). Farmers' Bounty: Locating Crop Diversity in the Contemporary World. Yale University Press: New Haven, CT, USA.

Brush S, Perales H (2007). A maize landscape: ethnicity and agro-biodiversity in Chiapas Mexico. Agric Ecosyst Environ 121: 211-221.
Doebley JF, Goodman M, Stuber CW (1985). Isozyme variation in the races of maize from Mexico. Am J Bot 72: 629-639.

Evanno G, Regnaut S, Goudet J (2005). Detecting the number of clusters of individuals using the software STRUCTURE: a simulation study. Mol Ecol 14: 2611-2620.

Excoffier L, Laval G, Schneider S (2005). Arlequin (version 3.0): an integrated software package for population genetics data analysis. Evol Bioinform Online 1: 47.

Excoffier L, Smouse PE, Quattro JM (1992). Analysis of molecular variance inferred from metric distances among DNA haplotypes: application to human mitochondrial DNA restriction data. Genetics 131: 479-491.

Harlan J (1975). Crops and Man. American Society of Agronomy: Madison, WI, USA.

Hernández XE (1972). Exploración etnobotánica en maíz. Fitotecnia latinoamericana 8: 46-51.

INEGI (2013). Conjunto de datos vectoriales de la serie topográfica y de recursos naturales escala 1:1000 000. INEGI: Mexico.

Kaufman T (1990). Early Otomanguean homelands and cultures: some premature hypotheses. University of Pittsburgh Working Papers in Linguistics, Vol. 1, pp 91-136.

Labeyrie V, Deu M, Barnaud A, Calatayud C, Buiron M, Wambugu P et al. (2014). Influence of ethnolinguistic diversity on the sorghum genetic patterns in subsistence farming systems in Eastern Kenya. PLoS One 9: e92178.

Louette D, Smale M (2000). Farmers' seed selection practices and traditional maize varieties in Cuzalapa, Mexico. Euphytica 113: 25-41.

Maffi L (2005). Linguistic, cultural, and biological diversity. Annu Rev Anthropo/ 34: 599-617.

Matsuoka Y, Vigouroux Y, Goodman M, Sanchez J, Buckler E, Doebley J (2002). A single domestication for maize shown by multilocus microsatellite genotyping. Proc Natl Acad Sci USA 99: 6080-6084.

Mercer K, Martínez-Vásquez A, Perales HR (2008). Asymmetrical local adaptation of maize landraces along an altitudinal gradient. Evol App/ 1: 489-500.

Messeguer J, Peñas G, Ballester J, Bas M, Serra J, Salvia J, Palaudelmàs M, Melé E (2006). Pollen-mediated gene flow in maize in real situations of coexistence. Plant Biotechnol J 4: 633-645.

Oksanen J, Blanchet FG, Kindt R, Legendre P, Minchin PR, O'Hara RB et al. (2015). Vegan: Community Ecology Package. R package version 2.1-1. Available at: http://cran. r-project.org/package = vegan (accessed 10 May 2015).

Orozco-Ramírez Q (2014). Maize Diversity and Population Structure Related to Ethnolinguistic Variation. PhD Dissertation, University of California: Davis, CA, USA.

Orozco-Ramírez Q, Brush SB, Grote MN, Perales H (2014). A minor role for environmental adaptation in local-scale maize landrace distribution: results from a common garden experiment in Oaxaca, Mexico. Econ Bot 68: 383-396.

Ortega-Paczka R (2003). La diversidad del maíz en México. In: Esteva G, Marielle C (eds), Sin maíz no hay pais. Consejo Nacional para la Cultura y las Artes, Dirección General de Culturas Populares: Mexico, pp 123-154.

Perales H, Benz B, Brush S (2005). Maize diversity and ethnolinguistic diversity in Chiapas, Mexico. Proc Natl Acad Sci USA 102: 949-954.

Perales H, Brush S, Qualset CO (2003). Landraces of maize in Central Mexico: an altitudinal transect. Economic Bot 57: 7-20.

Pressoir G, Berthaud J (2004a). Population structure and strong divergent selection shape phenotypic diversification in maize landraces. Heredity 92: 95-101.

Pressoir G, Berthaud J (2004b). Patterns of population structure in maize landraces from the Central Valleys of Oaxaca in Mexico. Heredity 92: 88-94.

Pritchard JK, Stephens M, Donnelly P (2000). Inference of population structure using multilocus genotype data. Genetics 155: 945-959.

Pyhäjärvi T, Hufford MB, Mezmouk S, Ross-Ibarra J (2013). Complex patterns of local adaptation in teosinte. Genome Biol Evol 5: 1594-1609.

R Core Team (2014). R: A Language and Environment for Statistical Computing, ISBN 3-900051-07-0. R Foundation for Statistical Computing: Vienna, Austria. Available at: http://www.R-project.org (accessed 25 May 2014).

Slatkin M (1991). Inbreeding coefficients and coalescence times. Genet Res 58: 167-175.

Sánchez J, Goodman M (1992). Relationships among the Mexican races of maize. Economic Bot 46: 72-85.

Sánchez J, Goodman M, Stuber C (2000). Isozymatic and morphological diversity in the races of maize of Mexico. Economic Bot 54: 43-59.

Takuno S, Ralph P, Swarts K, Elshire RJ, Glaubitz JC, Buckler ES, Hufford MB, Ross-Ibarra J (2015). Independent molecular basis of convergent highland adaptation in maize. Genetics 200: 1297-1312.

van Etten J, Fuentes López M, Molina Monterroso L, Ponciano Samayoa K (2008). Genetic diversity of maize (Zea mays L. ssp. mays) in communities of the western highlands of Guatemala: geographical patterns and processes. Genet Resour Crop Ev 55: 303-317.

van Heerwaarden J (2007). Population Genetics of Traditionally Managed Maize: Farming Practice as a Determinant of Genetic Structure and Identity of Maize Landraces in Mexico. PhD Dissertation Wageningen University: The Netherlands.

van Heerwaarden J, van Eeuwijk F, Ross-Ibarra J (2010). Genetic diversity in a crop metapopulation. Heredity 104: 28-39.

van Heerwaarden J, Doebley J, Briggs WH, Glaubitz JC, Goodman MM, de Jesus Sanchez Gonzalez J et al. (2011). Genetic signals of origin, spread, and introgression in a large sample of maize landraces. Proc Natl Acad Sci USA 108: 1088-1092.

Vigouroux Y, Glaubitz J, Matsuoka Y, Goodman M, Sánchez J (2008). Population structure and genetic diversity of New World maize races assessed by DNA microsatellites. Am J Bot 95: 1240-1253.

Wright S (1951). The genetical structure of populations. Ann Eugen 15: 323-354.

Zimmerer K (1996). Changing Fortunes: Biodiversity and Peasant Livelihood in the Peruvian Andes. University of California Press: Berkeley, CA, USA.

Supplementary Information accompanies this paper on Heredity website (http://www.nature.com/hdy) 